\title{
Sistem pemantauan tetesan cairan infus berbasis Internet of Things
}

\author{
Trisiani Dewi Hendrawati $^{1^{*}}$, Rafi Aditya Ruswandi ${ }^{2}$ \\ ${ }^{1,2}$ Program Studi Teknik Komputer, Politeknik Sukabumi \\ Jl. Babakan Sirna No. 25 Kota Sukabumi, Jawa Barat 43132, Indonesia \\ ${ }^{1 *}$ trisianidewi@polteksmi.ac.id, ${ }^{2}$ rafiadityaruswandi@gmail.com
}

\begin{abstract}
ABSTRAK
Pemantauan cairan infus adalah sebuah metode untuk mengetahui laju cairan infus dengan menggunakan indikator tetesan cairan pada sistem infus tersebut. Sistem ini dapat membantu pasien dan perawat dalam penggantian cairan infus secara berkala. Penelitian ini bertujuan untuk melakukan pemantauan tetesan cairan infus secara otomatis berbasis Internet of Things (IoT) sehingga dapat mencegah kehabisan cairan infus atau tidak terkontrol oleh perawat. Perancangan sistem monitoring ini yaitu menggunakan sensor infrared, modul mikrokontroler Arduino, dan data dikirim melalui radio frekuensi. Hasil pengujian menunjukan jarak maksimal antara base-hotspot yaitu 3,5 meter. Sistem monitoring ini akan menampilkan data berupa tetesan cairan dengan status ON dan OFF secara realtime dengan rata-rata delay 2 detik.
\end{abstract}

Kata kunci: radio frekuensi, infrared, Arduino, IoT

\section{ABSTRACT}

Infusion fluid monitoring is a method to determine the condition of the fluid system rate by using liquid droplets in the infusion system. This system can help patients and nurses in changing intravenous fluids periodically. This study aims to monitor automatic intravenous fluid droplets based on Internet of Things (IoT) so that it can prevent infusion fluids from running out or not being controlled by nurses. The design of this monitoring system uses an infrared sensor, Arduino microcontroller module and data is sent via radio frequency. The test results show that the maximum distance between base-hotspot is 3.5 meters. This monitoring system will display data in the form of liquid droplets with the status $O N$ and OFF in realtime with average delay of 2 seconds.

Keywords: frequency radio, infrared, Arduino, IoT

\section{PENDAHULUAN}

Peralatan elektronika dapat diterapkan dalam berbagai hal, salah satunya dalam bidang medis yang ditempatkan di rumah sakit ataupun puskesmas. Berdasarkan hal tersebut sangat diperlukan peralatan medis yang mebutuhkan ketepatan dan kepresisian yang tinggi dikarenakan berhubungan dengan nyawa seseorang, sehingga ketika penggunaannya tidak benar atau terdapat kesalahan maka akan sangat fatal akibatnya. Beberapa peralatan elektronika yang dikembangkan salah satunya yaitu sistem yang dapat memantau cairan infus pada pasien [1]. Tujuan dari infus adalah mengurangi dehidrasi akibat kehilangan cairan atau zat makanan melalui sebuah jarum yang dimasukkan ke dalam pembuluh vena dan mengalir dari tempat yang lebih tinggi menuju ke tempat yang lebih rendah sehingga tetesan cairan infus akan selalu mengalir ke tubuh pasien [2].

Salah satu tanggung jawab perawat terhadap pasien yaitu memastikan laju arus infus yang sudah ditentukan oleh dokter agar tetap terjaga sehingga pasien tetap merasa nyaman dan memastikan keselamatan pasien [3]. Masalah yang berhubungan dengan penggunaan infus konvensional saat ini yaitu kurangnya pengetahuan penunggu pasien tentang laju cairan infus dan mengatur sendiri laju cairan infus tersebut sehingga dapat menimbulkan efek pada pasien. Maka dari itu, diperlukan sebuah alat elektronika yang dapat memantau cairan infus pada pasien. Sistem pemantauan cairan infus adalah sebuah metode untuk mengetahui tetesan air secara berkala. Pasien tidak perlu khawatir dengan cairan infus yang masih ada atau habis. Karena dapat diketahui dan dipantau secara langsung di ruang server 
perawat. Perawat pun tidak perlu melakukan cek secara langsung ke ruangan pasien secara berkala. Pengecekan dapat dilakukan secara periodik di ruang server. Dengan demikian dapat dipastikan waktu yang tepat cairan infus diganti.

Beberapa penelitian sebelumnya telah dilakukan mengenai pemantauan tetesan cairan infus. Sistem monitoring infus telah dirancang menggunakan sensor light emitting diode (LED) dan photodiode dengan pengontrol utamanya adalah mikrokontroler AVR ATMega16 [4]. Penelitian yang serupa dilakukan oleh [5] yaitu menggunakan sensor photodiode dan pengaturan laju infusnya menggunakan motor servo. Kemudian penelitian selanjutnya yang dilakukan oleh [6] yaitu sistem monitoring dengan sensor yang digunakan adalah photodiode dan LED infra merah. Prinsip kerja dari sistem ini mendeteksi tetesan yang berada pada chamber infus. Kemudian penelitian yang dilakukan oleh [7] menggunakan sensor photodiode yang akan mengirimkan data dari katup selang infus dan diproses di mikrokontroler. Kemudian fungsi dari lampu LED adalah sebagai indicator peringatan kondisi pasien sesuai yang sudah ditetapkan. Penelitian selanjutnya merancang proses pengiriman data tetesan infus menggunakan modul radio frekuensi, sedangkan sensor yang digunakan adalah sensor infrared [8]. Kemudian penelitian yang dilakukan oleh [9] bertujuan untuk memilah data tentang tetesan per menit cairan infus dan level cairan infus, serta membuat aplikasi yang dapat menampilkan informasi tentang tetesan per menit cairan infus dan level cairan infus di desktop. Terakhir, penelitian yang serupa juga dilakukan oleh [10] dengan sensor yang digunakan adalah sensor berat sehingga ketika kantong infus mendekati habis maka laju aliran infus akan terhenti.

Tujuan dari penelitian ini adalah untuk merancang sistem pemantauan laju arus infus sehingga ketika terjadi gangguan akan terdeteksi oleh sistem yang dibuat. Perancangan perangkat keras ini menggunakan sensor infrared. Data diproses pada mikrokontroler Arduino yang selanjutnya data dikirim melalui modul radio frekuensi NRF24L01, dimana node mengirimkan data ke satu titik koordinat yaitu base. Kemudian base mengolah data yang diterima dari node serta dapat mengirimkan data tersebut ke website yang dibuat menggunakan modul WiFi untuk koneksi kejaringan internet sekaligus berfungsi untuk menyimpan data pada database server.

\section{METODE PENELITIAN}

\subsection{Perancangan Perangkat Keras}

Diagram blok sistem pemantauan etesan cairan infus otomatis berbasis IoT ditunjukan pada Gambar 1. Berdasarkan diagram tersebut, dapat dilihat bahwa hasil dari pembacaan sensor infrared diproses oleh mikrokontroler menjadi data yang diinginkan yaitu nilai pembacaan tetesan cairan infus. Node tersebut mengirimkan data ke base melalui sinyal radio frekuensi. Selanjutnya, data yang diterima oleh base diproses melalui mikrokontroler. Data dari node pada base tersebut ditampilkan pada liquid crystal display (LCD) dan dikirim ke database melalui jaringan WiFi. Perancangan perangkat keras ini dibuat hanya satu node dan satu base.

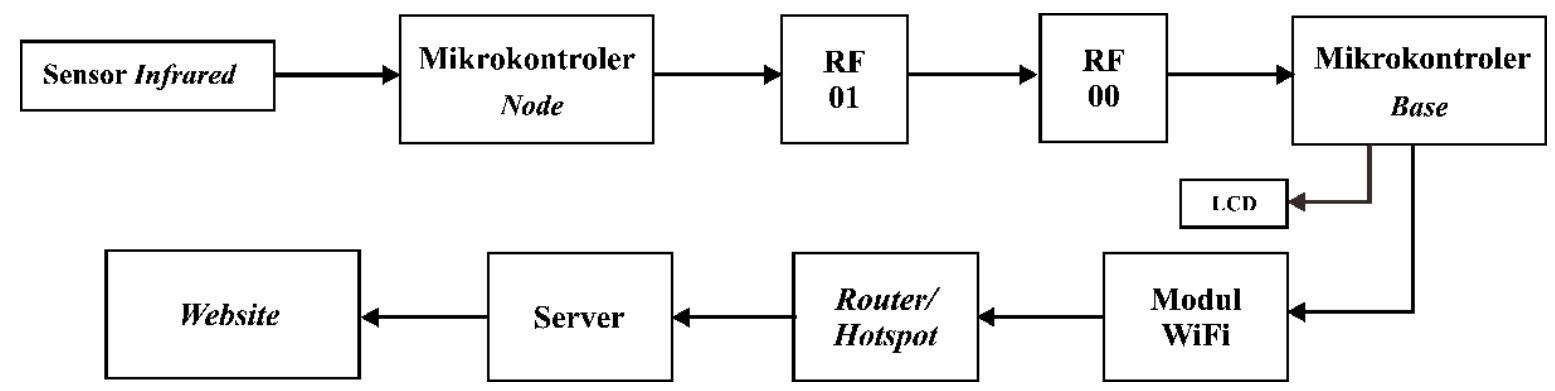

Gambar 1. Diagram blok secara keseluruhan

Adapun activity diagram sistem ini ditunjukan pada Gambar 2. Sistem yang dirancang terdiri dari beberapa perangkat hardware yang diperlukan untuk membangun sistem diantaranya, Arduino Nano dan Mega2560 sebagai mikrokontroler proses pengolahan data, modul radio frekuensi NRF24L01 digunakan untuk pengiriman paket data dari node ke base dengan jarak yang telah ditentukan. Modul ESP8266 digunakan sebagai pengiriman data ke server melalui router/hotspot sebagai jembatan penghubung antara sensor dengan database dan website dengan jaringan internet. 


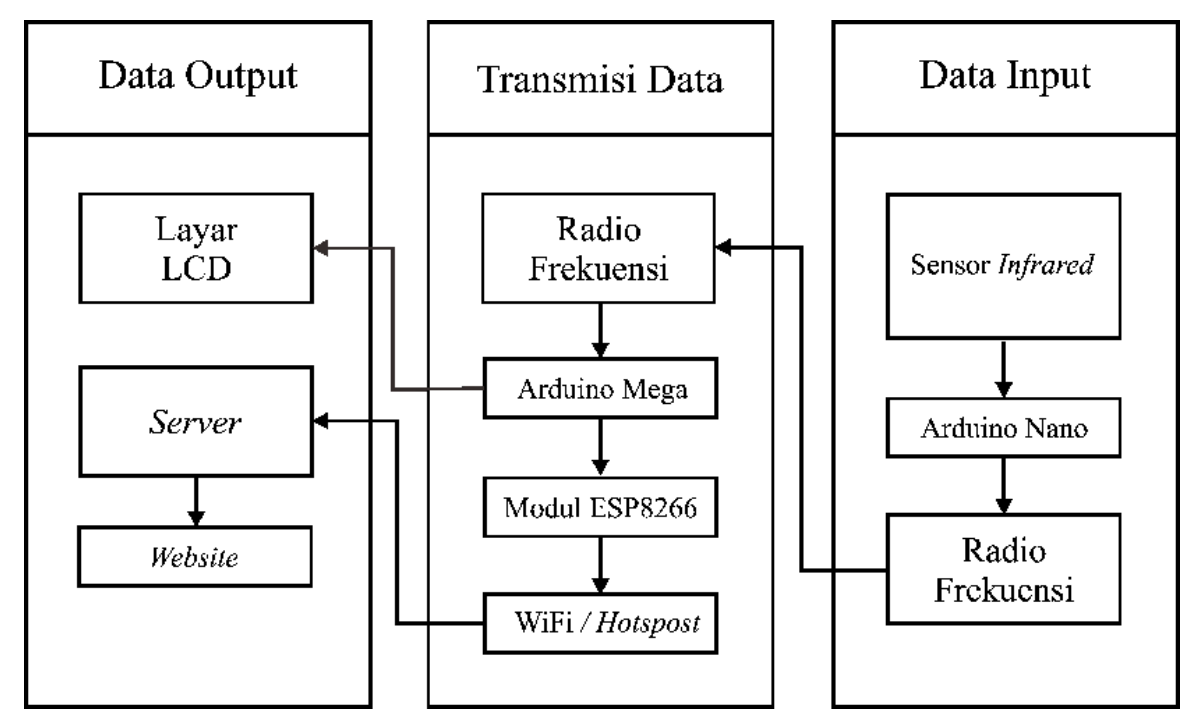

Gambar 2. Activity diagram sistem

Tabel 1 menampilkan spesifikasi perancangan pada perangkat keras yang digunakan untuk sistem pemantauan tetesan cairan infus.

Tabel 1. Spesifikasi perangkat keras

\begin{tabular}{|l|l|}
\hline \multicolumn{1}{|c|}{ Spesifikasi } & \multicolumn{1}{c|}{ Keterangan } \\
\hline Modul mikrokontroler & - Arduino Nano \\
& - Arduino Mega2560 \\
\hline Sensor & - Infrared TCRT 5000 \\
\hline Media pengiriman data & - NRF4L01 + PA + LNA Antena \\
& - Modul WiFi ESP8266 \\
\hline Media jaringan & - Router/Modem/Hotspot (Smartphone) \\
\hline Kabel & - Jumper Male to Male \\
& - Jumper Male to Female \\
& - Jumper Female to Female \\
\hline Bahan tambahan & - LCD \\
& - Cairan infus \\
& - LED \\
& - Push button \\
& - Switch \\
\hline
\end{tabular}

Adapun rangkaian NRF24L01 dengan mikrokontroler pada bagian node dapat dilihat pada Gambar 3, rangkaian sensor infrared dengan mikrokontroler pada bagian node pada Gambar 4, dan rangkaian modul ESP8266 dengan mikrokontroler pada bagian base pada Gambar 5.

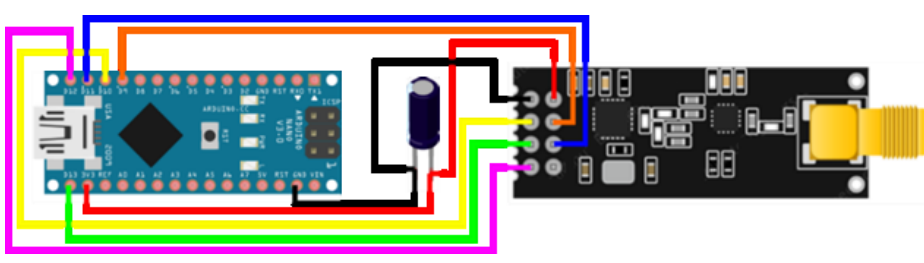

\begin{tabular}{|c|c|c|}
\hline NRF24L01 & & Arduino Nano \\
\hline Kabel merah (VCC) & $\rightarrow$ & Kapasitor (+) 3,3V \\
\hline Kabel hitam (GND) & $\rightarrow$ & Kapasitor (-) GND \\
\hline Kabel kuning (CE) & $\rightarrow$ & D10 \\
\hline Kabel hijau (SCK) & $\rightarrow$ & D13 \\
\hline Kabel pink (MISO) & $\rightarrow$ & D12 \\
\hline Kabel orange (CSN) & $\rightarrow$ & D9 \\
\hline Kabel biru (MOSI) & $\rightarrow$ & D11 \\
\hline
\end{tabular}

Gambar 3. Rangkaian NRF4L01 dihubungkan dengan mikrokontroler pada bagian node 


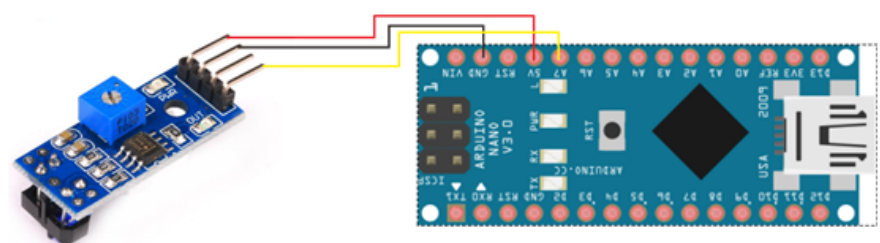

$\begin{array}{llll}\quad \text { Sensor infrared } & & \text { Arduino Nano } \\ \text { Kabel merah (VCC) } & \rightarrow & 5 \mathrm{~V} \\ \text { Kabel hitam(GND) } & \rightarrow & \text { GND } \\ \text { Kabel kuning(A0) } & \rightarrow & \text { A7 }\end{array}$

Gambar 4. Rangkaian sensor infrared dengan mikrokontroler di bagian node

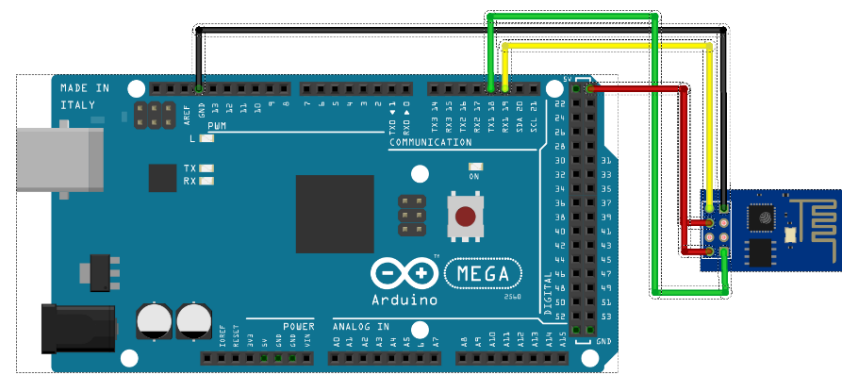

\begin{tabular}{llll}
\multicolumn{1}{c}{ Modul ESPS266 } & & Arduino Mega \\
Kabel kuning(RX) & $\rightarrow$ & TX \\
Kabel hitam(GND) & $\rightarrow$ & GND \\
Kabel merah(VCC) & $\rightarrow$ & $3,3 \mathrm{~V}$ \\
Kabel merah(CH_PD) & $\rightarrow$ & $3,3 \mathrm{~V}$ \\
Kabel hijau(TX) & $\rightarrow$ & RX
\end{tabular}

\section{Gambar 5. Rangkaian modul ESP8266 di bagian base}

\subsection{Perancangan Perangkat Lunak}

Beberapa tahapan dalam perancangan perangkat lunak untuk sistem yang dirancang diantaranya adalah perancangan program Arduino IDE yang akan ditanam pada mikrokontroler node dan base, Sublime Text 3 sebagai aplikasi text editor, dan MySQL digunakan sebagai penyimpanan data sensor berupa database. Pada perancangan atau pemograman di Arduino IDE ini, secara garis besar alur logika yang dibuat pada perancangan ini dapat dilihat pada Gambar 6. Diagram alir ini kemudian diimplementasikan ke dalam bahasa pemrograman $\mathrm{C} / \mathrm{C}++$ pada Arduino IDE.
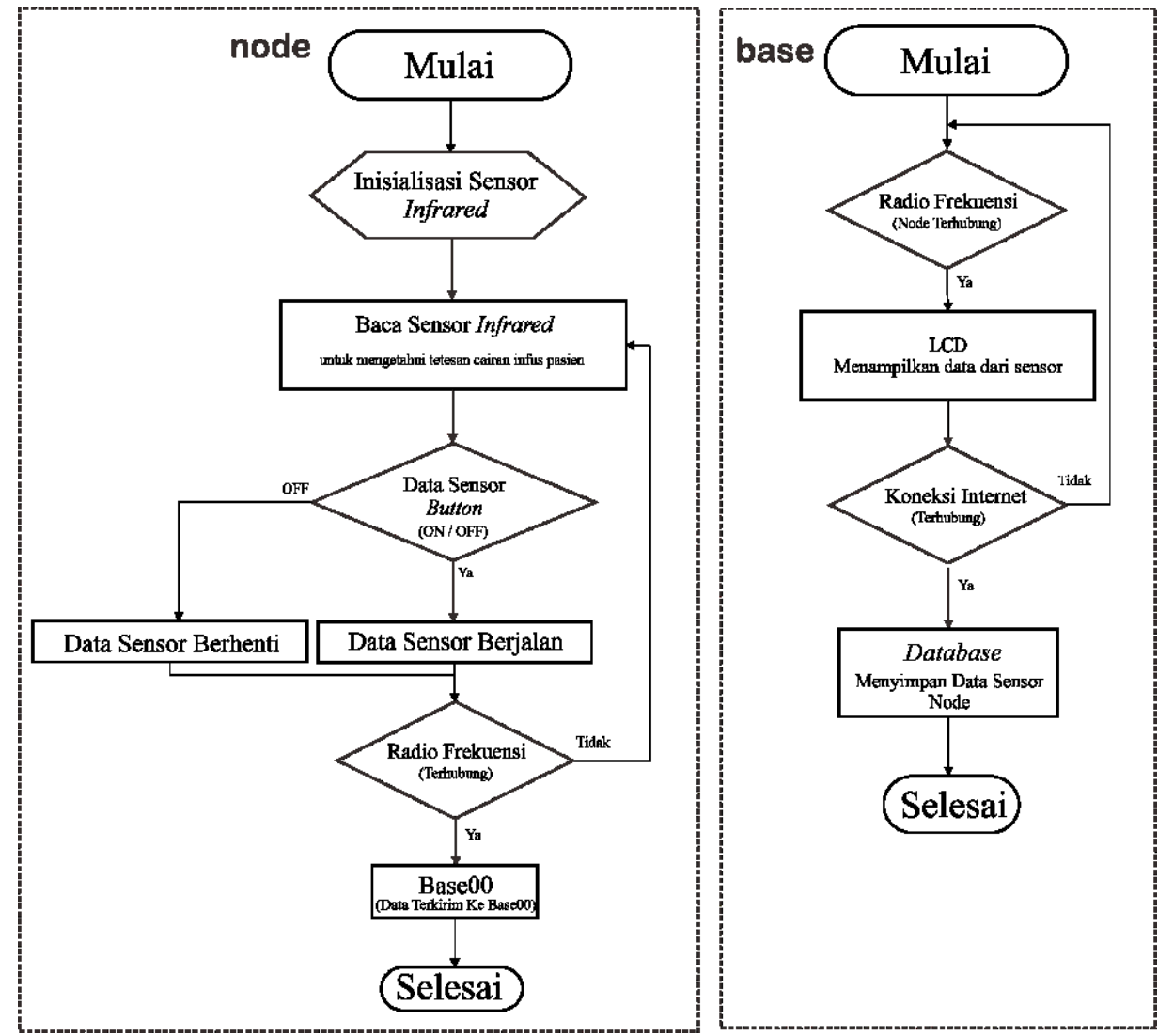

Gambar 6. Flowchart progam Arduino IDE pada node dan base 
Pada perancangan database, data atau nilai sensor dari node disimpan pada database MySQL. Pusat data (base) mengirimkan data tersebut melalui sebuah jaringan internet. Nama database sistem ini yaitu db_monitor_infus, sedangkan pada setiap tabel diantaranya tabel users digunakan untuk login ke dalam website dan tabel tb_node digunakan untuk menyimpan data sensor. Struktur tabel yang digunakan untuk perancangan database terdapat pada Gambar 7.

\begin{tabular}{|c|}
\hline $\mathbf{v} \mathbf{d b}$ monitor infus users \\
\hline id : int(10) unsigned \\
\hline (1) nama : varchar(100) \\
\hline email : varchar(100) \\
\hline 自 role : varchar(2) \\
\hline 自 password : varchar(255) \\
\hline remember_token : varchar $(100)$ \\
\hline 1] created_at : timestamp \\
\hline 1) updated_at : timestamp \\
\hline
\end{tabular}

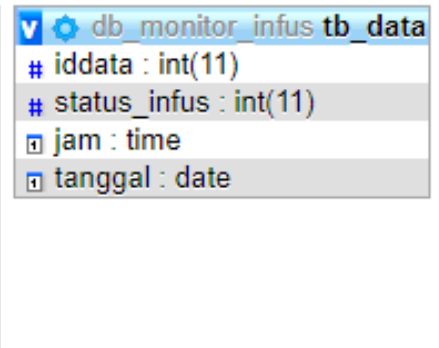

\section{Gambar 7. Tabel pada database sistem}

Pada perancangan interface website, sistem dirancang agar dapat menampilkan nilai database secara real-time atau sesuai dengan waktu yang ditentukan pada halaman website yaitu berupa informasi tetesan cairan infus. Website yang dibuat menyediakan empat node dan nanti dapat dikembangkan sesuai kebutuhan pengguna.

\section{HASIL DAN PEMBAHASAN}

\subsection{Implementasi Perangkat Keras}

Implementasi perangkat keras dari sistem yang dirancang dapat dilihat pada Gambar 8. Terdapat node yang berfungsi untuk mendeteksi tetesan cairan infus pada pasien diantaranya sensor infrared sebagai pembaca tetesan cairan infus, Arduino Nano sebagai mikrokontroler, dan button untuk menghentikan sementara dan menjalankan kembali program pengamatan yang dibantu dengan indikator LED merah sebagai penanda bahwa program pengamatan berhenti dan LED hijau penanda bahwa program berjalan. Kemudian terdapat NRF24L01 sebagai pengirim data sensor melalui jaringan frekuensi radio ke base. Bagian base berfungsi untuk menerima hasil pengamatan node diantaranya NRF24L01 sebagai penerima data sensor yang dikirimkan, Arduino Mega sebagai mikrokontroler, LCD menampilkan data sensor, dan ESP8266 sebagai pengirim data sensor melalui jaringan internet agar data sensor dapat ditampilkan dan dilihat pada website.
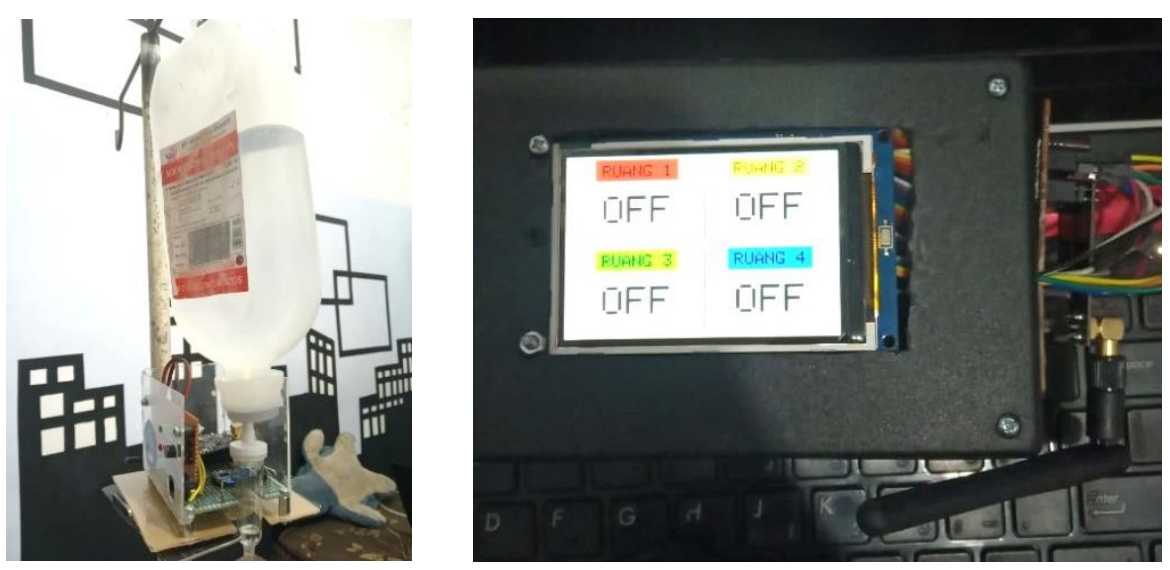

Gambar 8. Implementasi perangkat keras node (kiri) dan base (kanan)

\subsection{Pengujian Sensor Infrared}

Sensor yang digunakan pada sistem ini yaitu sensor infrared TCRT5000. Pengujian dilakukan dengan tujuan untuk mengetahui kinerja dari sensor tersebut. Pengujian dilakukan dengan cara mengamati status pada LCD saat terjadi tetesan cairan. Adapun hasil pengujian dapat dilihat pada Tabel 2. 
Tabel 2. Pengujian sensor infrared TCRT5000

\begin{tabular}{|c|c|c|}
\hline No. & Tetesan & Status \\
\hline 1 & YA & "ON" \\
\hline 2 & TIDAK & "OFF" \\
\hline 3 & YA & "ON" \\
\hline 4 & TIDAK & "OFF" \\
\hline 5 & YA & "OFF" \\
\hline 6 & TIDAK & "ON" \\
\hline 7 & YA & "OFF" \\
\hline 8 & TIDAK & "ON" \\
\hline 9 & YA & OFF" \\
\hline 10 & TIDAK & \\
\hline
\end{tabular}

Berdasarkan hasil pengujian, dapat diketahui sensor infrared dapat mendeteksi adanya tetesan cairan infus. Ketika sensor mendapatkan input berupa tetesan cairan infus maka LCD sebagai indikator akan menunjukkan pemeberihatuan "ON". Sebaliknya, jika sensor tidak mendapatkan input berupa tetesan cairan infus, maka LCD sebagai indikator akan menunjukkan pemberihatuan "OFF".

\subsection{Pengujian Modul Radio Frekuensi}

Pengujian ini dilakukan untuk mengetahui jarak maksimal komunikasi data antara node dengan base menggunakan modul NRF24L01. Dengan adanya ujicoba ini, maka akan didapatkan gambaran umum untuk jarak pemasangan alat sensor yang akan ditempatkan pada setiap ruangan. Hasil pengujian modul radio frekuensi dapat dilihat pada Tabel 3.

Tabel 3. Pengujian komunikasi radio frekuensi antara node dengan base

\begin{tabular}{|c|c|c|c|c|c|}
\hline No. & Tempat percobaan & $\begin{array}{c}\text { Jarak } \\
\text { (maks.) }\end{array}$ & $\begin{array}{c}\text { Jarak } \\
\text { (rekomendasi) }\end{array}$ & $\begin{array}{c}\text { Sinyal } \\
\text { RF }\end{array}$ & $\begin{array}{c}\text { Delay } \\
\text { (detik) }\end{array}$ \\
\hline 1 & Ruang terbuka (lapangan) & $\pm 7 \mathrm{~m}$ & $\pm 6 \mathrm{~m}$ & SB & 0 \\
\hline 2 & $\begin{array}{l}\text { Ruang tertutup (ruangan kelas } \\
\text { A dengan kelas B) }\end{array}$ & $\pm 4 \mathrm{~m}$ & $\pm 3 \mathrm{~m}$ & $\mathrm{SP}$ & 5 \\
\hline 3 & $\begin{array}{l}\text { Ruang terbuka dengan ruang } \\
\text { tertutup }\end{array}$ & $\pm 5 \mathrm{~m}$ & $\pm 47 \mathrm{~m}$ & SP & 2 \\
\hline 4 & $\begin{array}{l}\text { Lantai atas dengan lantai } \\
\text { bawah }\end{array}$ & $\pm 8 \mathrm{~m}$ & $\pm 7 \mathrm{~m}$ & SB & 0 \\
\hline 5 & Lantai atas dengan lapangan & $\pm 8 \mathrm{~m}$ & $\pm 7 \mathrm{~m}$ & SB & 2 \\
\hline \multicolumn{6}{|c|}{ Keterangan: } \\
\hline $\begin{array}{l}\text { SB } \\
\text { SP }\end{array}$ & $\begin{array}{l}\text { : Sinyal Bagus (komunikasi RF } \\
\text { : Sinyal Putus-putus (komunikas }\end{array}$ & $\begin{array}{l}\text { ar) } \\
\text { F tidak lan }\end{array}$ & & & \\
\hline
\end{tabular}

Berdasarkan hasil pengujian, maka dapat diketahui jarak maksimal dan rekomendasi pengiriman data melalui jaringan frekuensi radio dari node ke base. Jarak rekomendasi merupakan jarak yang disarankan pada pemasangan alat agar data dapat terkirim dengan stabil. Jarak maksimal merupakan jarak node dengan base masih dapat terkoneksi tetapi data yang diterima tidak akan stabil. Data pengujian tersebut merupakan gambaran umum atau acuan dasar pemasangan jarak alat dengan base. Adapun hal lain yang perlu diperhatikan yaitu kondisi cuaca dan tempat pengamatan, dimana akan sangat berpengaruh terhadap koneksi jaringan frekuensi radio. 


\subsection{Pengujian Sistem IoT}

Pengujian IoT dalam sistem yang dirancang ini terdapat tiga pengujian diantaranya adalah mengetahui jarak koneksi data dari base dengan hotspot/router agar dapat terhubung dengan database, durasi pengiriman data dari base ke database, dan tampilan dan kegunaan pada halaman di dalam website. Tabel 4 adalah hasil pengujian jarak koneksi jaringan dengan durasi pengiriman data. Berdasarkan hasil pengujian, diperoleh bahwa jarak maksimal antara perangkat base dengan hotspot adalah 3,5 meter dengan durasi pengiriman data sekitar 5 detik.

Tabel 4. Jarak koneksi jaringan base-hotspot

\begin{tabular}{|c|c|c|c|}
\hline Pengujian & $\begin{array}{c}\text { Jarak } \\
\text { (maksimal) }\end{array}$ & $\begin{array}{c}\text { Durasi } \\
\text { (terkoneksi) }\end{array}$ & Keterangan \\
\hline 1 & 2 meter & 3 detik & Normal \\
\hline 2 & 2,5 meter & 3 detik & Normal \\
\hline 3 & 3 meter & 4 detik & Normal \\
\hline 4 & 3,5 meter & 5 detik & Normal \\
\hline 5 & 4 meter & Tidak Terkoneksi & Tidak Normal \\
\hline
\end{tabular}

Gambar 9 merupakan tampilan halaman awal pada website pemantauan tetesan cairan infus. Pada halaman ini data ditampilkan secara realtime. Perancangan monitoring infus ini dibuat satu node dan satu base, tetapi untuk perancangan websitenya sudah disediakan untuk empat node sehingga kedepannya dapat dikembangkan sesuai kebutuhan pengguna. Berdasarkan Gambar 9, kotak berwarna biru untuk node 1, kotak berwarna hijau untuk node 2, kotak berwarna orange untuk node 3, dan kotak berwarna merah untuk node 4.

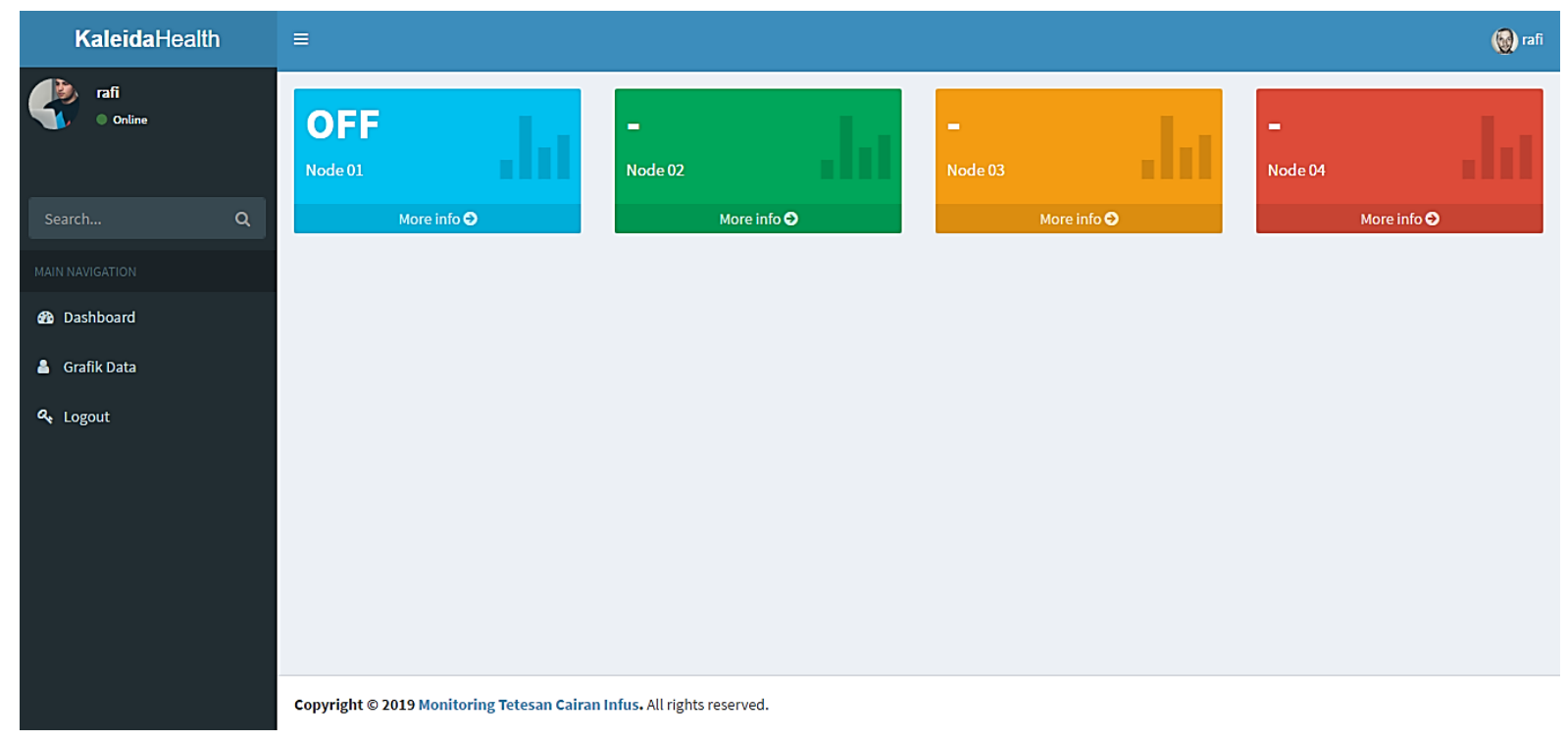

Gambar 9. Tampilan halaman dashboard

\section{KESIMPULAN}

Sistem pemantauan tetesan cairan infus telah berhasil dirancang guna untuk mempermudah perawat melakukan tugasnya. Data dari sistem infus tersebut berupa tetesan cairan yang dibaca oleh sensor infrared dan dikirimkan oleh transmitter dan diterima receiver yang berasal dari sensor yang terpasang pada infus. Berdasarkan hasil pengujian, jarak koneksi jaringan maksimal yang diterima adalah antara base dan hotspot adalah sekitar 3,5 meter, sedangkan durasi pengiriman datanya yaitu 2 detik. Pengembangan selanjutnya dapat ditambahkan sumber listrik yang digunakan dalam bentuk baterai, sehingga dapat mengantisipasi ketika listrik mati. Selain itu juga dapat ditambahkan sistem yang dapat mendeteksi jumlah volume cairan infus sehingga tidak terjadi lagi cairan infus yang habis tanpa sepengetahuan perawat. 


\section{UCAPAN TERIMA KASIH}

Ucapan terima kasih disampaikan kepada Laboratorium Elektro, Politeknik Sukabumi yang mendukung dalam penyediaan fasilitas penelitian ini sehingga penelitian dapat diselesaikan dengan baik.

\section{REFERENSI}

[1] M. Hasanuddin, "Sistem Monitoring Infus Menggunakan Arduino Mega 2560," Universitas Islam Negeri Alauddin Makassar, 2017.

[2] R. A. Primahayu, F. Utaminingrum, and D. Syauqy, "Sistem Monitoring Cairan Infus Terpusat Menggunakan Pengolahan Citra Digital," J. Pengemb. Teknol. Inf. dan Ilmu Komput. Univ. Brawijaya, vol. 1, no. 8, pp. 649-657, 2017.

[3] D. Sasmoko and Y. A. Wicaksono, "IMPLEMENTASI PENERAPAN INTERNET of THINGS (IoT) PADA MONITORING INFUS MENGGUNAKAN ESP 8266 DAN WEB UNTUK BERBAGI DATA,” $J$. Ilm. Inform., vol. 2, no. 1, pp. 90-98, 2017.

[4] N. Muljodipo, S. R. U. A. Sompie, R. F. Robot, M. Eng, J. T. Elektro-ft, and E. Nuryantomuljodipogmailcom, "Rancang Bangun Otomatis Sistem Infus Pasien," J. Tek. Elektro dan Komput., vol. 4, no. 4, pp. 12-22, 2015.

[5] G. P. Mahardhika and M. Herawati, "Rancang Bangun Perangkat Pengendali Debit Tetesan Infus Otomatis Untuk Proses Terapi Infus," Semin. Nas. Inform. Medis VI, p. 21, 2015.

[6] D. NATALIANA, N. TARYANA, and E. RIANDITA, "Alat Monitoring Infus Set pada Pasien Rawat Inap Berbasis Mikrokontroler ATmega 8535,” ELKOMIKA J. Tek. Energi Elektr. Tek. Telekomun. Tek. Elektron., vol. 4, no. 1, p. 1, 2018.

[7] N. Lestari, "Rancang Bangun Sistem Monitoring Sisa Cairan Iinfus dan Monitoring Aliran Infus Berbasis Arduino Di Puskesmas Muara Beliti," Pros. SNATIF, vol. 2, no. 1, pp. 21-27, 2017.

[8] P. Iriyanto, "Rancang Bangun Sistem Alarm Infus Otomatis," Universitas Lampung, 2018.

[9] E. D. P. S. Putra, G. I. Hapsari, and Gi. A. Mutiara, "Pembangunan Perangkat Monitoring Cairan Infus Dengan Menggunakan Nrf24L01," e-Proceeding Appl. Sci., vol. 4, no. 3, p. 2047, 2018.

[10] K. N. T. Yayer, W. A. Weliamto, R. Sitepu, and H. Pranjoto, "Monitoring Dan Penghentian Cairan Infus Menggunakan Timbangan Infus Digital Dengan Memanfaatkan Web Server," Simetris J. Tek. Mesin, Elektro dan Ilmu Komput., vol. 11, no. 1, pp. 55-64, 2020. 